\title{
The effects of co-witness discussion on confidence and precision in eyewitness memory reports
}

Citation for published version (APA):

Rechdan, J., Hope, L., Sauer, J. D., Sauerland, M., Ost, J., \& Merckelbach, H. (2018). The effects of cowitness discussion on confidence and precision in eyewitness memory reports. Memory, 26(7), 904-912. https://doi.org/10.1080/09658211.2018.1448872

Document status and date:

Published: 01/01/2018

DOI:

10.1080/09658211.2018.1448872

Document Version:

Publisher's PDF, also known as Version of record

Document license:

Taverne

Please check the document version of this publication:

- A submitted manuscript is the version of the article upon submission and before peer-review. There can be important differences between the submitted version and the official published version of record.

People interested in the research are advised to contact the author for the final version of the publication, or visit the DOI to the publisher's website.

- The final author version and the galley proof are versions of the publication after peer review.

- The final published version features the final layout of the paper including the volume, issue and page numbers.

Link to publication

\footnotetext{
General rights rights.

- You may freely distribute the URL identifying the publication in the public portal. please follow below link for the End User Agreement:

www.umlib.nl/taverne-license

Take down policy

If you believe that this document breaches copyright please contact us at:

repository@maastrichtuniversity.nl

providing details and we will investigate your claim.
}

Copyright and moral rights for the publications made accessible in the public portal are retained by the authors and/or other copyright owners and it is a condition of accessing publications that users recognise and abide by the legal requirements associated with these

- Users may download and print one copy of any publication from the public portal for the purpose of private study or research.

- You may not further distribute the material or use it for any profit-making activity or commercial gain

If the publication is distributed under the terms of Article $25 \mathrm{fa}$ of the Dutch Copyright Act, indicated by the "Taverne" license above, 


\section{The effects of co-witness discussion on confidence and precision in eyewitness memory reports}

Joanne Rechdan, Lorraine Hope, James D. Sauer, Melanie Sauerland, James Ost \& Harald Merckelbach

To cite this article: Joanne Rechdan, Lorraine Hope, James D. Sauer, Melanie Sauerland, James Ost \& Harald Merckelbach (2018) The effects of co-witness discussion on confidence and precision in eyewitness memory reports, Memory, 26:7, 904-912, DOI: $10.1080 / 09658211.2018 .1448872$

To link to this article: https://doi.org/10.1080/09658211.2018.1448872

册Published online: 13 Mar 2018.

Submit your article to this journal 준

山ll Article views: 1758

Q View related articles $\sqsubset$

View Crossmark data

Citing articles: 1 View citing articles $\sqsubset$ 


\title{
The effects of co-witness discussion on confidence and precision in eyewitness memory reports
}

\author{
Joanne Rechdan ${ }^{\mathrm{a}, \mathrm{b}}$, Lorraine Hope ${ }^{\mathrm{a}}$, James D. Sauer ${ }^{\mathrm{c}}$, Melanie Sauerland ${ }^{\mathrm{b}}$, James Ost ${ }^{\mathrm{a}}$ and \\ Harald Merckelbach ${ }^{\mathrm{b}}$ \\ ${ }^{\mathrm{a} D e p a r t m e n t ~ o f ~ P s y c h o l o g y, ~ U n i v e r s i t y ~ o f ~ P o r t s m o u t h, ~ P o r t s m o u t h, ~ U K ; ~}{ }^{\mathrm{b}}$ Department of Clinical Psychological Science, Faculty of Psychology \\ and Neuroscience, Maastricht University, Maastricht, Netherlands; 'Division of Psychology, University of Tasmania, Hobart, Australia
}

\begin{abstract}
We examined the influence of co-witness discussion on the metacognitive regulation of memory reports. Participants $(N=92)$ watched a crime video. Later, a confederate confidently agreed with (gave confirming feedback), disagreed with (gave disconfirming feedback), or gave no feedback (control) regarding participants' answers to questions about the video. Participants who received disconfirming feedback reported fewer fine-grain details than participants in the confirming and control conditions on a subsequent, individual recall test for a different question set. Unexpectedly, this decrease in fine-grain reporting was not accompanied by a decrease in participants' confidence in the accuracy of their fine-grain responses. These results indicate that receiving social comparative feedback about one's memory performance can affect rememberers' metamemorial control decisions, and potentially decrease the level of detail they volunteer in later memory reports. Further research is needed to assess whether these results replicate under different experimental conditions, and to explore the effects of social influences on metamemory.
\end{abstract}

ARTICLE HISTORY

Received 24 March 2017

Accepted 25 February 2018

\section{KEYWORDS}

Metacognition; eyewitness memory; social influence; cowitness discussion; memory reporting
It is a well-established finding in the eyewitness literature that memory reports can be distorted by exposure to post-event information (PEl; Frenda, Nichols, \& Loftus, 2011; Wright, Self, \& Justice, 2000). Eyewitnesses sometimes incorporate $\mathrm{PEI}$ in their reports following discussions with co-witnesses, exhibiting memory conformity (Gabbert \& Hope, 2013; Gabbert, Memon, \& Allan, 2003). There are several reasons why memory conformity between co-witnesses may occur. In some instances, one witness may report details learned from another in order to avoid the perceived social costs of disagreeing (Cialdini \& Goldstein, 2004), a form of conformity known as normative influence (Deutsch \& Gerard, 1955). Memory conformity may also be the result of informational influence, which occurs when one person reports information she has learned from another because she feels this information is accurate (Deutsch \& Gerard, 1955). Finally, memory conformity may be the result of memory distortion (Gabbert, Wright, Memon, Skagerberg, \& Jamieson, 2012). Witnesses may report details learned through discussion with a cowitness because they have forgotten the source of the information (source misattribution; Zaragoza \& Lane, 1994).

Memory conformity resulting from normative and informational social influences does not necessarily reflect an alteration of the memory itself, but rather, of the memory report (Blank, 2009; Blank, Walther, \& Isemann, 2017).
According to the revised dual-criterion model, the content of memory reports is determined through metacognitive monitoring and control (Ackerman \& Goldsmith, 2008; Goldsmith, Koriat, \& Weinberg-Eliezer, 2002; Koriat \& Goldsmith, 1996). When reporting information from memory, people subjectively assess their confidence in the accuracy of candidate responses, as well as how informative they are likely to be for a receiver through monitoring (Ackerman \& Goldsmith, 2008). They then set subjective cutoffs (criteria) for accuracy and informativeness that must be met in order for a candidate response to be reported - this is known as control. Control criteria can be met by adjusting the precision (level of detail, or grain size) of a response, such as by reporting either detailed fine-grain (e.g., the sweater was navy blue) or less detailed coarse-grain (e.g., the sweater was dark) information. Essentially, the rememberer starts with as detailed a candidate response as can be retrieved from memory, and adjusts the grain size of the response (making it coarser as necessary) until it meets both accuracy and informativeness criteria. Candidate responses that do not meet these criteria are withheld, which can improve the accuracy of memory reports (Ackerman \& Goldsmith, 2008; Koriat \& Goldsmith, 1996).

Eyewitness reports can make a critical contribution to the success of criminal investigations (Semmler, Brewer,

CONTACT Joanne Rechdan joanne.rechdan@gmail.com Department of Psychology, University of Portsmouth, King Henry I Street, Portsmouth P01 2DY, Hampshire, UK 
\& Bradfield Douglass, 2012); it is therefore important to understand if and how PEl exchanged between co-witnesses influences the metacognitive processes that govern memory reporting. The possible effects of cowitness discussion on metacognitive monitoring and control of memory reporting have yet to be empirically tested. In the present experiment, we manipulated agreement/disagreement with a co-witness and examined its effect on participants' monitoring of the accuracy of their candidate responses (measured by self-reported confidence) and control (measured by the quantity and precision of the information they chose to report). It is important to note that the focus of the present research is memory reporting, or what witnesses say when questioned about their memory for an event, as opposed to their actual memory for the event (which may include more information or different details than they choose to explicitly report). Although there is research evidence that memory for events can be altered through discussion (see Hirst \& Echterhoff, 2012, for a review), our focus is on how discussion between co-witnesses may affect memory reports, specifically through its potential effects on the metacognitive monitoring and control processes responsible for the selection of reported details.

\section{The effects of co-witness discussion on memory reports}

To examine the effects of post-event discussion between co-witnesses on their individual memory reports, many studies have used a paradigm in which members of a cowitness dyad are exposed to versions of stimuli that differ in some respects (critical items) (Gabbert et al., 2003; Gabbert, Memon, \& Wright, 2007; Wright et al., 2000, Experiment 2; Wright, Gabbert, Memon, \& London, 2008). They are then instructed to discuss what they have seen prior to having their recall tested. Members of each co-witness dyad are given the impression that they have seen the same stimuli, when in fact they have each seen a different version. For example, in Gabbert et al. (2003), participants watched one of two videos of a theft shot from different perspectives, each of which included unique details. Results showed that over $70 \%$ of participants later reported details they had not seen in the video, but were only exposed to through discussion with their co-witness. Subsequent research has replicated Gabbert et al.'s findings, demonstrating a robust memory conformity effect (Wright, Memon, Skagerberg, \& Gabbert, 2009).

In an alternative paradigm, Meade, Michelle and Roediger III (2002) showed participant and confederate dyads pictures of typical household scenes. In a collaborative recall phase, confederates named some items that had not actually appeared in the scenes. Later, when participants completed an individual recall test, they sometimes incorporated items that had been mentioned by confederates but were not actually present in the original scenes.
These results demonstrate the contamination of memory reports through verbal interaction, which Meade et al. (2002) termed social contagion of memory. While the terms social contagion and memory conformity have been used interchangeably, we have used the term memory conformity throughout this paper to maintain consistency.

Certain factors may increase the likelihood, or predict the occurrence, of memory conformity. For example, Gabbert, Memon, Allan, and Wright (2004) found that PEI encountered through face-to-face communication was more misleading than PEl embedded in a written narrative. Further studies have shown that witnesses who volunteer information first in the course of a discussion are more likely to influence their co-witnesses' memory reports, and that members of co-witness dyads are more likely to conform to information provided by the more confident member (Gabbert et al., 2006, Experiment 1; Wright et al., 2000). Gabbert et al. (2007) found that participants' beliefs about the quality of their memory in comparison to a co-witnesses' affected their susceptibility to misinformation. Participants who were told they had encoded a set of pictures for half as long as a co-witness were more likely to report erroneous details mentioned by that cowitness than were participants told they had encoded the pictures for twice as long. Participants who believed they had seen pictures for twice as long mentioned more details during a discussion with a co-witness, and were more likely to mention critical items first. More recently, research on memory conformity has found that both directly (via a co-witness) and indirectly (in a written report) encountered $\mathrm{PEI}$ can result in memory conformity (Blank et al., 2013); that conformity effects are increased when the source of information is seen as highly credible (Horry, Palmer, Sexton, \& Brewer, 2012); and that participants' confidence in the accuracy of their memory reports can be influenced by a confederate's expressed confidence (Goodwin, Hannah, Nicholl, \& Ferri, 2017; Goodwin, Kukucka, \& Hawks, 2013; Thorley \& Kumar, 2017).

Individuals sometimes seek information from external sources to bolster the accuracy and informativeness of their recall when internal evidence is weak (Bless, Strack, \& Walther, 2001; Horry et al., 2012; Jaeger, Lauris, Selmeczy, \& Dobbins, 2012). Jaeger et al. (2012) examined the influence of judgments made by external sources on participants' memory. In two experiments, participants completed a computerised recognition task in which they had to identify words on a list as previously studied ('old') or newly presented ('new'). For some of the words, participants were shown a bogus judgment made by peers on screen just before the target word. The cues were accurate on $75 \%$ of trials for one of the sources ("reliable"), and $50 \%$ of trials for the other source ("unreliable"). Results showed that participants conformed to judgments made by the "unreliable" source about as often as they conformed to judgments made by the "reliable" source, indicating that they did not seem to distinguish between the reliability of the two sources. Thus, 
it seems that in a social comparative context, people are not very good at determining the recall accuracy of others. Furthermore, participants conformed to judgments made by the external sources when their confidence in the accuracy of their own memory was low. This strategy, referred to as low confidence outsourcing, meant that while conformity to cues from the "reliable" source improved accuracy, conformity to cues from the "unreliable" source neither hindered nor improved accuracy relative to participants' baseline recognition performance.

In an adaptation of the paradigm used by Jaeger et al. (2012), Zawadzka, Krogulska, Button, Higham, and Hanczakowski (2016) found that participants still conformed to judgments from external sources when they had the option to withhold responses (Experiments 1 and 2). However, participants' decisions to withhold certain responses were not influenced by the cues from the sources - in other words, the manipulation resulted in memory conformity but not metamemory conformity. They also found that when participants were given feedback regarding the accuracy of the sources, they were able to distinguish between the reliable and unreliable source, as evidenced by their metacognitive control decisions (Experiment 3). Following this feedback, participants conformed to the judgments of the reliable source more often than those of the unreliable source, and also withheld more responses on trials with a cue from an unreliable source compared to trials with a cue from a reliable source (Zawadzka et al., 2016).

The results of Jaeger et al. (2012) and Zawadzka et al. (2016; Experiment 1) show that people strategically use information from external sources to bolster their own memory. While people are more likely to conform to sources they perceive as reliable, overall, people are poor judges of source reliability. In the real world, rememberers usually have no objective indications of an external sources' reliability. The low confidence outsourcing strategy can therefore lead rememberers to incorporate potentially errant PEI when they cannot confidently recall certain details. Memory conformity may not affect metamemory however, as Zawadzka et al. (2016; Experiments 1 and 2) found that when source reliability was undetermined, memory conformity occurred without influencing response withholding.

\section{Metacognitive monitoring and control of memory reports}

Once a memory has been retrieved and reconstructed, rememberers determine which details to report through metacognitive monitoring and control (Koriat \& Goldsmith, 1996). A few studies have examined the effects of metacognitive monitoring and control on eyewitness reports of episodic memories (Evans \& Fisher, 2011; McCallum, Brewer, \& Weber, 2016; Sauer \& Hope, 2016; Weber \& Brewer, 2008). The two-phase paradigm used in most of these studies was adapted from Koriat and Goldsmith
(1996). In the first phase of the paradigm, participants give fine- and coarse-grain answers to questions, and provide ratings of their confidence in the accuracy of these answers (0-100\%); in the second phase, they select one of their answers as a preferred response, and are sometimes given the option to withhold a response. Using this paradigm, in two experiments, Weber and Brewer (2008) found that the level of detail participants chose to report was related to their confidence in their fine-grain answers. If participants were highly confident that a detailed answer was accurate, they were more likely to report it.

McCallum et al. (2016) investigated grain-size volunteering and recall confidence in different social conditions. In two experiments, participants answered questions about a witnessed mock crime in the two-phase question format. The results of Experiment 1 showed that confidence significantly predicted response accuracy. Furthermore, participants who were told that their responses would remain private were nearly twice as likely to volunteer fine-grain responses as participants who were told that they would have to respond to questions publicly. In Experiment 2, a monetary incentive with penalties for inaccurate responses was introduced. When there was no penalty for inaccurate reporting, participants showed a bias for volunteering fine-grain answers. The results of these two experiments suggest that the presence of others, and the potential for negative consequences for inaccuracy can alter rememberer's' control strategies.

Metacognitive monitoring and control can also be influenced by conditions at encoding. Sauer and Hope (2016) examined the strategic regulation of memory reporting for information encoded in conditions of full and divided attention. They found that participants in the divided attention condition provided fewer fine-grain responses, volunteered less accurate fine-grain responses, and expressed lower confidence in their fine-grain responses than participants in the full attention condition. Therefore, while participants in the divided attention condition monitored the accuracy of their responses successfully, they chose to sacrifice accuracy for informativeness. In line with the revised dual-criterion model, findings from these experiments show that individuals place a heavy emphasis on informativeness.

In an attempt to be as informative as possible, individuals may draw on information from various sources, including PEl they have encountered through discussion with cowitnesses. Individuals control the content of their memory reports through metacognitive monitoring and control, and can improve the accuracy and informativeness of their reports by these means. It is therefore possible that co-witness discussion affects memory reporting through its influence on the metacognitive processes underlying the selection of reported details. We examined whether disagreement among participants over details of a jointly witnessed mock crime event influenced their metacognitive regulation of their memory reports. Investigating 
metacognitive decisions that potentially underlie memory conformity can inform the development of investigative interviewing techniques. Additionally, such an investigation may further our understanding of how metamemorial monitoring and control operate under various conditions, which is of theoretical value.

In the current experiment, we examined the effects of social comparative feedback provided by a co-witness on participants' (a) confidence in the accuracy of their recall, (b) volunteering of fine- and coarse-grain responses, (c) withholding of responses, and (d) response accuracy on a subsequent memory assessment. Our primary interest was not the actual content/accuracy of individual responses - but rather whether the social manipulation affected confidence, thereby influencing the selection of details to be volunteered or withheld. We predicted that, relative to confirming feedback and no feedback, receiving disconfirming feedback from a co-witness would decrease participants' confidence in the accuracy of their memory at Phase I, and therefore reduce the proportion of fine-grain responses they volunteered at Phase II (Ackerman \& Goldsmith, 2008; Weber \& Brewer, 2008). We expected that participants who received confirming feedback would show increased confidence in the accuracy of their answers at Phase I, and therefore be likely to volunteer more finegrain responses at Phase II than participants in the disconfirming feedback group. We also examined the effect of feedback on participants' withholding of details. Lower confidence in the accuracy of a candidate response reduces the chances that it will be reported (Ackerman \& Goldsmith, 2008), so we predicted that participants who received disconfirming feedback would withhold more responses than participants in the confirming and no feedback groups. Participants in this experiment were not given misinformation about details they were subsequently questioned about; this was done so that we could examine the potential effects of disagreement between co-witnesses during a discussion on their subsequent memory reports independently of the misinformation effect. We therefore expected that the accuracy of participants' answers to questions on the cued recall task would not be affected by the manipulation.

\section{Method}

\section{Design}

In a between-subjects design, we manipulated feedback across three conditions: confirming feedback $(n=32)$, disconfirming feedback $(n=30)$, or no feedback $(n=30)$, and examined the effects on participants' confidence, the grain size of the details they volunteered, and their withholding of details.

\section{Participants}

Ninety-two individuals participated in the study (64 females, 28 males, $M_{\text {age }}=30.1$ years; $S D=12.9$ ). Sample size was determined based on sample sizes used in similar studies (Ackerman \& Goldsmith, 2008; Weber \& Brewer, 2008). Participants were university staff and students. Criteria for participation included being at least 18 years old, being fluent in English, and having normal, or corrected to normal vision. Ethical approval for the experiment was obtained from the university's science faculty research ethics committee.

\section{Materials}

\section{Stimulus event}

Participants viewed a three-minute video event depicting a theft. In the event, a man gains access to an elderly couple's home under the pretense of adjusting their electricity meter. He distracts them while an accomplice surreptitiously enters the house and steals valuables from the second floor of the property.

\section{Recall questions}

Questions included in the practice task and the cued recall task referred to details from the video. In the practice task, participants were asked to provide both fine- and coarsegrain written answers to six questions. They were also asked to provide a rating of their confidence in the accuracy of each answer on a scale of $0-100 \%$ (10\% increments). These questions referred to the male victim in the video (e.g., "What was the colour of the male victim's vest?" A fine-grain answer to this question might be "navy blue", while a coarse-grain answer might be "dark"). The practice task questions were presented in a paper booklet.

The cued recall task was modelled after the standard two-phase approach used in previous studies of metacognitive monitoring and control of memory reports (Ackerman \& Goldsmith, 2008; Goldsmith et al., 2002; Weber \& Brewer, 2008). The task was comprised of 22 cued recall questions (e.g., What colour was the getaway car?; How many items did the perpetrators steal from the home?), and was completed electronically. None of the questions in the practice task were repeated in the cued recall task.

\section{Pilot testing}

Prior to data collection, we conducted a pilot focus group session with six volunteer participants (all female, aged 18-25 years) who watched the stimulus video used in the experiment on individual laptops, with sound played through headphones. Afterwards, they were asked to write their answers to the six practice task questions used in the experiment. After completing the practice task, participants were then asked to rate the difficulty of each question on a 7-point scale ranging from 1 (very easy) to 7 (very difficult). On the basis of these ratings, two questions were classified as "easy" (average rating between 1 and 2); two questions as medium difficulty (average rating between 3 and 5); and two questions as difficult (average rating between 6 and 7). To select our critical 
items for the experiment, we judged that having a confederate disagree with answers that seemed blatantly obvious (easy questions) might raise participants' suspicions about the authenticity of the manipulation. We also thought it might be suspicious for confederates to produce the exact same answers to questions that the participants perceived to be very difficult to recall. We therefore decided that in order to uphold the plausibility and integrity of the experimental manipulation, agreement and disagreement by the confederate should not be complete, but rather, should be with the majority (4/6) of the participants' responses. Thus, in the confirming condition, confederates were instructed to agree with the participant's answers to four of the six questions, but to disagree with their answers to the two questions rated most difficult to answer by the pilot focus group. In the disconfirming condition, confederates were instructed to disagree with four of the participant's answers, but to agree with their answers to the two questions rated easiest to answer by the pilot focus group. Confederates were told to respond as instructed regardless of the actual accuracy of participant's responses. In nearly all of the studies we have reviewed in which a confederate was used to provide feedback or introduce misinformation, agreement or disagreement between the confederate and participants was not complete (e.g., Meade \& Roediger III, 2002; Goodwin et al., 2017).

\section{Procedure}

After signing an informed consent form, participants were randomly allocated to one of the three conditions (confirming feedback, disconfirming feedback, no feedback). Participants in all conditions viewed the videos as part of a dyad. Participants in the no feedback condition viewed the video with another participant while participants in the disconfirming and confirming feedback conditions viewed the video in the presence of a confederate who they were led to believe was another participant recruited in the same manner as themselves. There were four female confederates, each of whom was randomly assigned to participate in a roughly equal number of trials (15 or 16). All participants then completed the practice task. Participants were told that the purpose of the practice task was to familiarise them with the format of the questions they would be answering on the cued recall task. While the practice task did include instructions about what coarse- and fine-grain responses were, it was primarily a means for delivering social comparative feedback prior to the cued recall task. Participants in the two feedback conditions took turns with the confederate in verbally relaying their answers to the practice task questions in the presence of the experimenter. The experimenter asked the participant to begin, so that he/she always provided answers and confidence ratings before the confederate. Depending on the condition, the confederate either agreed or disagreed with the majority (4/6) of the fine-grain answers provided by the participant (by giving the same or a different answer), and expressed high confidence in these responses (by verbally stating a confidence rating of $80 \%, 90 \%$, or $100 \%)$. Participants in the control condition did not report their answers to the practice questions aloud.

After completing the practice task, all participants moved into separate rooms to complete the cued recall task individually. In Phase I of the cued recall task, participants provided fine- and coarse-grain answers with confidence ratings ranging from $0 \%$ to $100 \%$ in $10 \%$ increments (higher ratings indicating higher confidence levels) to each of the 22 questions. Phase I of the task was forced-report, meaning participants had to provide both fine- and coarse-grain answers before they could advance to the next phase. In Phase II, participants were presented with their answers from Phase I (without confidence ratings), and instructed to select either the fine- or coarse-grain response for each question as their final answer. Participants again provided confidence ratings for their volunteered answers. The instructions for Phase Il were as follows:

Now I would like you to imagine that you are a real eyewitness to the crime you have just seen in the video. The police officer interviewing you requests that you choose ONE of the two answers that you provided to each of the questions above.

Participants were also instructed to be as accurate as possible and not guess when they were providing their answer. After selecting either the coarse- or fine-grain answer they volunteered in Phase I, participants moved to Phase III (note: in Phase II, an increase in fine-grain responding automatically resulted in a decrease in coarse-grain responding). In Phase III, participants were shown the answers they provided in Phase II of the task (final answers), and were asked if they would prefer to withhold their responses to any of the questions. The instructions for Phase III were as follows:

\footnotetext{
You will now have a chance to review the final answers you have chosen. In this section, you have the option of choosing to refrain from responding to questions (choosing 'I don't know') should you decide that the response you provided earlier is not suitable.
}

Previous research has shown that individuals can improve the accuracy of their memory reports if they have the option to withhold responses (Koriat \& Goldsmith, 1996). After completing the cued recall task, all participants were thanked and debriefed. The entire procedure took approximately 30 minutes.

\section{Results}

Data were roughly normally distributed with no outliers for any of the dependent variables. One-way ANOVAs were conducted comparing group means for the confirming feedback, disconfirming feedback, and control (no feedback) conditions for the following dependent variables: expressed confidence in the accuracy of fine- and coarsegrain responses at Phase I, grain-size volunteering at 
Table 1. Means, standard deviations, and 95\% confidence intervals for control, confirming and disconfirming conditions.

\begin{tabular}{|c|c|c|c|c|c|c|}
\hline \multirow[b]{2}{*}{ Dependent variable } & \multicolumn{2}{|c|}{ Control $(n=30)$} & \multicolumn{2}{|c|}{ Confirming $(n=32)$} & \multicolumn{2}{|c|}{ Disconfirming $(n=30)$} \\
\hline & $M(S D)$ & $95 \% \mathrm{Cl}$ & $M(S D)$ & $95 \% \mathrm{Cl}$ & $M(S D)$ & $95 \% \mathrm{Cl}$ \\
\hline Phase I CG confidence & $72.54(11.27)$ & {$[68.34 ; 76.76]$} & $78.91(8.50)$ & [75.84; 81.97] & $73.59(11.50)$ & {$[69.30 ; 77.88]$} \\
\hline Phase I FG confidence & $65.52(10.60)$ & {$[61.56 ; 69.48]$} & $69.26(10.20)$ & {$[65.58 ; 72.94]$} & $65.18(11.73)$ & {$[60.80 ; 69.56]$} \\
\hline Phase II CG volunteering & $9.50(2.78)^{\mathrm{a}}$ & {$[8.46 ; 10.54]$} & $10.28(2.63)^{b}$ & {$[9.33 ; 11.23]$} & $11.67(2.71)^{a, b}$ & {$[10.66 ; 12.68]$} \\
\hline Phase II FG volunteering & $12.50(2.78)^{\mathrm{a}}$ & {$[11.46 ; 13.54]$} & $11.72(2.63)^{b}$ & {$[10.77 ; 12.67]$} & $10.33(2.71)^{a, b}$ & {$[9.32 ; 11.34]$} \\
\hline Phase III withholding & $6.30(2.87)$ & {$[5.23 ; 7.37]$} & $5.75(2.74)$ & {$[4.76 ; 6.74]$} & $7.37(3.43)$ & {$[6.09 ; 8.65]$} \\
\hline Phase I CG accuracy & $16.43(3.09)$ & {$[15.28 ; 17.59]$} & $17.41(2.18)$ & {$[16.62 ; 18.20]$} & $16.67(2.83)$ & {$[15.61 ; 17.72]$} \\
\hline Phase I FG accuracy & $12.87(3.01)$ & {$[11.74 ; 14.00]$} & $13.22(2.85)$ & {$[12.20 ; 14.25]$} & $12.57(3.14)$ & {$[11.40 ; 13.74]$} \\
\hline
\end{tabular}

Note: Means in a row sharing the same superscript differ at $p<.05 . \mathrm{Cl}=$ confidence interval; $\mathrm{CG}=$ coarse grain; $\mathrm{FG}=$ fine grain .

Phase II, response withholding (selection of "I don"t know') at Phase III, and the accuracy of fine- and coarse-grain responses at Phase I. To control for increased error rate due to multiple comparisons, we applied a Bonferroni correction, dividing our standard alpha value of .05 by the number of statistical tests run (5). The result was a new alpha level of $p=.01$ to determine statistical significance. Table 1 shows control, disconfirming, and confirming group means and standard deviations for all dependent variables. Below, the results of the analyses are reported with conventional statistics alongside effect sizes.

The results of the ANOVAs showed no significant difference between groups for coarse-grain, $F(2,89)=3.32$, $p=.04, \omega^{2}=.09$ or fine-grain, $F(2,89)=1.36, p=.26$, $\omega^{2}=.01$ confidence at Phase I. There was also no significant difference between groups for response withholding at Phase III, $F(2,89)=2.28, p=.11, \omega^{2}=.07$. There was a significant effect of the manipulation on fine- and coarsegrain volunteering at Phase II, $F(2,89)=4.95, p=.009$, $\omega^{2}=.08$, with a medium effect size (Kirk, 1996). A choice between fine- and coarse-grain answers was forced in Phase II, meaning that an increase in volunteering for one type of answer necessitated a decrease for the other. We followed up this significant ANOVA with $t$-tests to compare each of the groups on grain-size volunteering. We ran three $t$-tests, which constituted a new family of statistical tests. The Bonferroni correction is very conservative, and therefore, we did not apply it for this series of $t$-tests, given that there were only three of them, and they followed a significant omnibus test for which the correction was applied. The results of the $t$-tests showed a significant difference between the control and disconfirming groups in volunteering of fine- and coarse-grain responses, $t(58)$ $=3.06 p=.003, d=0.78$. Participants in the disconfirming feedback group volunteered more coarse-grain $(M=$ 11.67, $S D=2.71)$, and fewer fine-grain $(M=10.33, S D=$ 2.71) answers than participants in the control group (coarse-grain $M=9.50, S D=2.78$; fine-grain $M=12.50, S D$ $=2.78$ ). There was also a significant difference in volunteering of fine- and coarse-grain answers between participants in the confirming and disconfirming groups, $t(60)=-2.04$, $p=.045, d=-0.51$. Participants in the disconfirming feedback group also volunteered more coarse-grain and fewer fine-grain answers than participants in the confirming group (coarse-grain $M=10.28, S D=2.63$; fine-grain $M$ $=11.72, S D=2.63)$. There was no significant difference between participants in the control and confirming groups for fine- and coarse-grain volunteering at Phase II, $t(60)=1.14, p=.26, d=0.28$. There were no other significant differences between groups, or effect sizes of note, including for accuracy.

\section{Discussion}

The present research examined the effects of receiving confirming or disconfirming feedback about the accuracy of one's memory on participants' reported confidence, grain-size volunteering, and response withholding in a subsequent recall task. Consistent with our predictions, we found that participants in the disconfirming condition reported significantly fewer fine-grain details than participants in the confirming or control conditions. Contrary to expectations however, this decrease in fine-grain responding did not correspond with a decrease in participants' expressed confidence in the accuracy of their fine-grain answers at Phase I. This is surprising, as previous research shows that fine-grain confidence at Phase I determines whether a fine-grain option is volunteered at Phase II (Ackerman \& Goldsmith, 2008; Goldsmith et al., 2002; Weber \& Brewer, 2008). However, the finding is not without precedent, as in Rechdan et al. (2017) we found no effects of positive and negative computer mediated social comparative feedback on participants' confidence in the accuracy of their memory reports. We expected that the manipulation in the present experiment, which involved a confederate challenging the participant on fine-grain details, would be quite salient, and result in reduced confidence for the accuracy of those details. Instead, the significant decrease in fine-grain volunteering in the absence of a decrease in confidence shown by participants in the disconfirming group suggests that the social feedback manipulation had an effect on participants' metacognitive control decisions (grain-size volunteering), but no effect on their metacognitive monitoring (as reflected by subjective confidence).

Disagreement with the co-witness (confederate) over the majority of answers on the practice task may have affected participants' memory self-efficacy. Feedback from others can affect memory self-efficacy (Berry, 1999); and memory self-efficacy impacts memory performance (Beaudoin \& Desrichard, 2011). Decreased memory selfefficacy may have led participants in the disconfirming 
feedback group to take a more cautious approach to reporting, if only because coarse-grain responses are more likely to be accurate than fine-grain responses (Yaniv \& Foster, 1995, 1997). Future research should examine the role of memory self-efficacy in metamemorial decision-making.

Alternatively, the results can be explained in terms of effects on control sensitivity, or the degree to which memory reporting is guided by metacognitive monitoring assessments (Goldsmith, Pansky, \& Koriat, 2014). It is possible that disconfirming feedback altered the usually strong correspondence between participants' confidence in the accuracy of their fine-grain responses (monitoring assessment), and their decision to volunteer these responses (control decision). Goldsmith et al. (2014) note that rememberers may rely strongly on their confidence assessments because they have "no access to the diagnosticity of their monitoring or because they have no better alternative (p. 485)". It is possible that participants viewed the feedback they received from the confederate as diagnostic of the quality of their memory for the stimulus event. Participants in the disconfirming condition may have come to believe that their monitoring assessments did not reliably predict the accuracy of their recall, and they were thus less likely to rely on these assessments when making decisions about what to report on the cued recall task. Further research is needed to measure control sensitivity in the various social contexts in which memory reporting can occur.

Finally, it is important to note that descriptively, participants in the confirming feedback condition also volunteered fewer fine-grain responses than those in the control group. While this difference was not significant in the present experiment, it merits further investigation. One possible explanation for this pattern is that publicly reporting results and engaging in comparison with the confederate placed an emphasis on accuracy, thereby changing participants' perception of the standards of memory reporting. Previous research has shown that public (as opposed to private) reporting can influence metacognitive monitoring and control decisions, such as the precision with which rememberers report details from memory, as well as the level of confidence participants express in the accuracy of their recall (McCallum et al., 2016; Shaw, Appio, Zerr, \& Pontoski, 2007). Another possible explanation is that participants in the confirming group also experienced some degree of disagreement with the confederate (on two out of the six practice task questions). This mild level of disagreement may have resulted in an effect similar to that experienced by participants in the disconfirming group, albeit a less impactful one. The latter explanation fits with the observed pattern of the group means for fine-grain volunteering; disconfirming < confirming < control.

\section{Limitations}

A potential limitation of this experiment is that all of the confederates were female, and less than a third of participants were male. Carli (2001) notes that males are generally more influential than women and tend to resist influence by women. It is therefore possible that the results presented here are tempered by the gender of our influencers (confederates). Future research examining the role of social influence on metamemory, as well as potential replications of this work should involve an equal number of confederates and participants of both genders.

Furthermore, participants in this experiment were not re-questioned about the details for which they received feedback from a confederate. This element of the experimental design, though deliberate, may limit the generalisability of our results. We were interested in examining the effects of disagreement or agreement with a cowitness - not exposure to misinformation - on participants' subsequent memory reports. However, in real life investigations, witnesses may be questioned about details of an event that they have already discussed with a co-witness. Further research is needed to determine the effects of receiving $\mathrm{PEl}$ (including misinformation) from a cowitness on participants' subsequent metamemorial reporting strategies regarding the details discussed.

\section{Conclusion}

The results of this experiment show that disagreement between co-witnesses (on items unrelated to the test items) may affect their subsequent memory reports, leading them to limit the level of detail they choose to volunteer. This potential for discussion between co-witnesses to affect their individual metacognitive control strategies for memory reporting merits further investigation. These results further our understanding of how rememberers regulate memory reporting in the social contexts in which it often occurs.

\section{Acknowledgements}

The first author would like to thank Ms. Feni Kontogianni, Ms. Maria Andrea Ramirez Tobon, Ms. Sapphire Payne, Ms. Sneha Suresh, and Ms. Celaine Cooper for their help with pilot testing and data collection.

\section{Disclosure statement}

No potential conflict of interest was reported by the authors.

\section{Funding}

This work was supported by a fellowship awarded from the Erasmus Mundus Joint Doctorate Program, the House of Legal Psychology (EMJD-LP; FPA 2013-0036, SGA 2014-1438) to Joanne Rechdan, cohort 2013.

\section{References}

Ackerman, R., \& Goldsmith, M. (2008). Control over grain size in memory reporting - With and without satisficing knowledge. Journal of Experimental Psychology: Learning, Memory, and Cognition, 34, 1224-1245. doi:10.1037/a0012938 
Beaudoin, M., \& Desrichard, O. (2011). Are memory self-efficacy and memory performance related? A meta-analysis. Psychological Bulletin, 137(2), 211-241. doi:10.1037/a0022106

Berry, J. M. (1999). Memory self-efficacy in its social cognitive context. In T. M. Hess \& F. Blanchard-Fields (Eds.), Social cognition and aging (pp. 70-98). San Diego, CA: Academic Press.

Blank, H. (2009). Remembering: A theoretical interface between memory and social psychology. Social Psychology, 40(3), 164-175. doi:10.1027/1864-9335.40.3.164

Blank, H., Ost, J., Davies, J., Jones, G., Lambert, K., \& Salmon, K. (2013). Comparing the influence of directly vs. Indirectly encountered postevent misinformation on eyewitness remembering. Acta Psychologica, 144, 635-641. doi:10.1016/j.actpsy.2013.10.006

Blank, H., Walther, E., \& Isemann, S. D. (2017). The past is a social construction: Susceptibility to social influence in (mis)remembering. In R. A. Nash \& J. Ost (Eds.), False and distorted memories (pp. 55-71). Abingdon: Psychology Press.

Bless, H., Strack, F., \& Walther, E. (2001). Memory as a target of social influence? Memory distortions as a function of social influence and metacognitive knowledge. In J. P. Forgas \& K. D. Williams (Eds.), Social influence: Direct and indirect processes (pp. 167-183). New York, NY: Psychology Press.

Carli, L. L. (2001). Gender and social influence. Journal of Social Issues, 57, 725-741. doi:10.1111/0022-4537.00238

Cialdini, R. B., \& Goldstein, N. J. (2004). Social influence: Compliance and conformity. Annual Review of Psychology, 55, 591-621. doi:10. 1146/annurev.psych.55.090902.142015

Deutsch, M., \& Gerard, H. B. (1955). A study of normative and informational social influences upon individual judgment. Journal of Abnormal and Social Psychology, 51(3), 629-636. doi:10.1037/ h0046408.

Evans, J. R., \& Fisher, R. P. (2011). Eyewitness memory: Balancing the accuracy, precision, and quantity of information through metacognitive monitoring and control. Applied Cognitive Psychology, 25, 501-508. doi:10.1002/acp.1722

Frenda, S. J., Nichols, R. M., \& Loftus, E. F. (2011). Current issues and advances in misinformation research. Current Directions in Psychological Science, 20, 20-23. doi:10.1177/0963721410396620

Gabbert, F., \& Hope, L. (2013). Suggestibility and memory conformity In A. Ridley, F. Gabbert, \& D. LaRooy (Eds.), Suggestibility in legal contexts: Psychological research and forensic implications (pp. 63-83). Hoboken: Wiley doi:10.1002/9781118432907.ch4

Gabbert, F., Memon, A., \& Allan, K. (2003). Memory conformity: Can eyewitnesses influence each other's memories for an event? Applied Cognitive Psychology, 17, 533-543. doi:10.1002/acp.885

Gabbert, F., Memon, A., Allan, K., \& Wright, D. B. (2004). Say it to my face: Examining the effects of socially encountered misinformation. Legal and Criminological Psychology, 9, 215-227. doi:10.1348/ 1355325041719428

Gabbert, F., Memon, A., \& Wright, D. B. (2007). I saw it for longer than you: The relationship between perceived encoding duration and memory conformity. Acta Psychologica, 124, 319-331. doi:10.1016/ j.actpsy.2006.03.009

Gabbert, F., Memon, A., \& Wright, D. B. (2006). Memory conformity: Disentangling the steps toward influence during a discussion. Psyhconomic Bulletin \& Review, 13, 480-485. doi:10.3758/ BF03193873

Gabbert, F., Wright, D. B., Memon, A., Skagerberg, E. M., \& Jamieson, K. (2012). Memory conformity between eyewitnesses. Court Review: The Journal of the American Judges Association, 48, 36-43.

Goldsmith, M., Koriat, A., \& Weinberg-Eliezer, A. (2002). Strategic regulation of grain size in memory reporting. Journal of Experimental Psychology: General, 131, 73-95. doi:10.1037// 0096-3445.131.1.73

Goldsmith, M., Pansky, A., \& Koriat, A. (2014). Metacognitive control of memory reporting. In T. J. Perfect \& D. S. Lindsay (Eds.), The SAGE handbook of applied memory (pp. 481-498). London: SAGE.
Goodwin, K. A., Hannah, P. J., Nicholl, M. C., \& Ferri, J. M. (2017). The confident co-witness: The effects of misinformation on memory after collaborative discussion. Applied Cognitive Psychology, 31, 225-235. doi:10.1002/acp.3320

Goodwin, K. A., Kukucka, J. P., \& Hawks, I. M. (2013). Co-witness confidence, conformity, and eyewitness memory: An examination of normative and informational social influences. Applied Cognitive Psychology, 27, 91-100. doi:10.1002/acp.2877

Hirst, W., \& Echterhoff, G. (2012). Remembering in conversations: The social sharing and reshaping of memories. Annual Review of Psychology, 63, 55-79. doi:10.1146/annurev-psych-120710-100340

Horry, R., Palmer, M. A., Sexton, M. L., \& Brewer, N. (2012). Memory conformity for confidently recognized items: The power of social influence on memory reports. Journal of Experimental Social Psychology, 48, 783-786. doi:10.1016/j.jesp.2011.12.010

Jaeger, A., Lauris, P., Selmeczy, D., \& Dobbins, I. G. (2012). The costs and benefits of memory conformity. Memory \& Cognition, 40, 101-112. doi:10.3758/s13421-011-0130-z

Kirk, R. E. (1996). Practical significance: A concept whose time has come. Educational and Psychological Measurement, 56, 746-759. doi:10.1177/0013164496056005002

Koriat, A., \& Goldsmith, M. (1996). Monitoring and control processes in the strategic regulation of memory accuracy. Psychological Review, 103, 490-517. doi:10.1037/0033-295X.103.3.490

McCallum, N. A., Brewer, N., \& Weber, N. (2016). Memorial monitoring and control: How confidence and social and financial consequences affect eyewitnesses' reporting of fine-grain information. Applied Cognitive Psychology, 30, 375-386. doi:10.1002/acp.3212

Meade, Michelle L., \& Roediger III, Henry L. (2002). Explorations in the social contagion of memory. Memory \& Cognition, 30, 995-1009. doi:10.3758/BF03194318

Rechdan, J., Sauer, J. D., Hope, L., Sauerland, M., Ost, J., \& Merckelbach, H. L. G. J. (2017). Computer mediated social comparative feedback does not affect metacognitive regulation of memory reports. Frontiers in Psychology: Cognition, 8, 1433. doi:10.3389/fpsyg.2017. 01433

Sauer, J., \& Hope, L. (2016). The effects of divided attention at study and reporting procedure on regulation and monitoring for episodic recall. Acta Psychologica, 169, 143-156. doi:10.1016/j.actpsy.2016. 05.015

Semmler, C., Brewer, N., \& Bradfield Douglass, A. (2012). Jurors believe eyewitnesses. In B. L. Cutler (Ed.), Conviction of the innocent: Lessons from psychological research (pp. 185-209). Washington, DC: American Psychological Association. doi:10.1037/13085-009

Shaw, J. S., Appio, L. M., Zerr, T. K., \& Pontoski, K. E. (2007). Public eyewitness confidence can be influenced by the presence of other witnesses. Law and Human Behavior, 31, 629-652. doi:10.1007/s10979006-9080-6

Thorley, C., \& Kumar, D. (2017). Eyewitness susceptibility to co-witness misinformation is influenced by co-witness confidence and own self-confidence. Psychology, Crime \& Law, 23, 342-360. doi:10. 1080/1068316X.2016.1258471

Weber, N., \& Brewer, N. (2008). Eyewitness recall: Regulation of grain size and the role of confidence. Journal of Experimental Psychology: Applied, 14, 50-60. doi:10.1037/1076-898X.14.1.50

Wright, D. B., Gabbert, F., Memon, A., \& London, K. (2008). Changing the criterion for memory conformity in free recall and recognition. Memory (Hove, England), 16(2), 137-148. doi:10.1080/09658210701836174

Wright, D. B., Memon, A., Skagerberg, E. M., \& Gabbert, F. (2009). When eyewitnesses talk. Current Directions in Psychological Science, 18(3), 174-178. doi:10.1111/j.1467-8721.2009.01631.x

Wright, D. B., Self, G., \& Justice, C. (2000). Memory conformity: Exploring misinformation effects when presented by another person. British Journal of Psychology, 91, 189-202. doi:10.1348/000712600161781

Yaniv, I., \& Foster, D. P. (1995). Graininess of judgment under uncertainty: An accuracy-informativeness tradeoff. Journal of Experimental Psychology: General, 124, 424-432. doi:10.1037/00963445.124.4.424 
Yaniv, I., \& Foster, D. P. (1997). Precision and accuracy of judgmental estimation. Journal of Behavioral Decision Making, 10, 21-32. doi:10.1002/(SICI)1099-0771(199703)10:1<21::AID-BDM243>3.0. $\mathrm{CO} ; 2-\mathrm{G}$

Zaragoza, M. S., \& Lane, S. M. (1994). Source misattributions and the suggestibility of eyewitness memory. Journal of Experimental
Psychology: Learning, Memory, and Cognition, 20(4), 934-945. doi:10.1037/0278-7393.20.4.934

Zawadzka, K., Krogulska, A., Button, R., Higham, P. A., \& Hanczakowski, M. (2016). Memory, metamemory, and social cues: Between conformity and resistance. Journal of Experimental Psychology: General, 145, 181-199. doi:10.1037/xge0000118 